\title{
Polycyclic aromatic hydrocarbons in pyrolysis of gasoline
} surrogates ( $n$-heptane/iso-octane/toluene)

\author{
Can Shao ${ }^{\mathrm{a}}$, Haoyi Wang ${ }^{\mathrm{a}}$, Nour Atef ${ }^{\mathrm{a}}$, Zhandong Wang ${ }^{\mathrm{a}}$, Bingjie Chen ${ }^{\mathrm{a}}$, Maram \\ Almalki $^{\mathrm{a}}$, Yan Zhang ${ }^{\mathrm{b}}$, Chuangchuang Cao ${ }^{\mathrm{b}}$, Jiuzhong Yang $^{\mathrm{b}}$, S. Mani Sarathy ${ }^{\mathrm{a}}$ \\ ${ }^{a}$ King Abdullah University of Science and Technology (KAUST), Clean Combustion Research Center (CCRC), Thuwal 23955- \\ 6900, Saudi Arabia \\ ${ }^{b}$ National Synchrotron Radiation Laboratory (NSRL), University of Science and Technology of China (USTC), Hefei, Anhui \\ 230029, P. R. China
}

Abstract: Toluene primary reference fuels (TPRFs), i.e., a ternary mixture of toluene, $n$-heptane and iso-octane, better match the combustion properties of real gasoline fuels compared to simpler binary $n$-heptane/iso-octane mixtures. While there has been significant research on combustion of $n$ heptane/iso-octane mixtures, fundamental data characterizing polycyclic aromatic hydrocarbons (PAHs) formation in TPRFs combusition is lacking, especially under pyrolysis conditions. In this work, the pyrolysis of two TPRF mixtures (TPRF70 and TPRF97.5), representing low octane (research octane number 70) and high octane (research octane number 97.5) gasolines, respectively, was studied in a jet-stirred reactor coupled with gas chromatography (GC) analysis and a flow reactor coupled with synchrotron vacuum ultraviolet photoionization molecular beam mass spectrometry (SVUV-PI-MBMS). The experiments indicate that pyrolysis of TPRF70 produced slightly higher benzene and naphthalene than TPRF97.5. In constrast, TPRF97.5 pyrolysis produced slightly higher phenanthrene and pyrene than TPRF70. The mole fraction profiles of aromatics from benzene to pyrene were used to validate TPRF kinetic models from the literature. Specifically, the KAUST-Aramco PAH Mech 1-GS kinetic model was updated to match and elucidate the experimental observations. The kinetic analysis reveals that propargyl radical is a crucial intermediate forming the benzene and naphthalene, while benzyl radical, generated from the dehydrogenation of toluene, plays an important role for larger PAHs formation.

\footnotetext{
${ }^{*}$ Corresponding author: E-mail: zhandong.wang@kaust.edu.sa (Z. Wang)
} 
54 Keywords: gasoline surrogate; PAHs; pyrolysis; jet-stirred reactor; synchrotron vacuum ultraviolet 55 photoionization molecular beam mass spectrometry

\section{1. Introduction}

Soot particles and their precursors polycyclic aromatic hydrocarbons (PAHs) emitted from onroad vehicles contribute to anthropogenic aerosol emissions, thereby harming the environment and human health $[1,2]$. Emission of these carcinogenic pollutants is expected to increase with the growing demand for light-duty vehicles powered by gas direct injection (GDI) engines. This type of engine is widely used in the transport sector because of its fuel efficiency; however, they are characterized by a higher tendency for soot formation [3]. research target for decades [4]. Fundamental data from well-defined reactors and kinetic modeling with detailed reaction pathways are promising tools to bridge the gap [4-8].The combustion properties of molecules representative of those in gasoline, such as normal-alkanes, branched alkanes, and aromatics have been extensively investigated, providing data to develop detailed reaction mechanism for PAHs.

Gasoline surrogates comprising binary, ternary or multi-component mixtures are used to mimic

71 gasoline combustion and guide the development of advanced combustion engine (ACE) technologies [4, 5, 9-11]. Among them, toluene primary reference fuel (TPRF) surrogates are ternary blends of toluene/n-heptane/iso-octane. The advantage of using a TPRF surrogate is to better match the composition and combustion properties (e.g., octane numbers [5]) of gasoline compared primary reference fuel (PRF, binary mixture of $n$-heptane/iso-octane). TPRFs emulate the aromatic, $n$ paraffinic and iso-paraffinic content in real gasolines, as these three classes represent more than $90 \%$ of the chemicals in commercial gasoline fuels [12]. The presence of aromatics in gasolines and their surrogates was observed to enhance PAHs formation $[4,13]$. 
Literature experimental studies on PAHs formation for TPRF surrogates is scarce, as the focus has been on binary mixtures. Choi et al. [14] studied PAHs and soot formation characteristics for binary mixtures in counter-flow diffusion flames using laser-induced fluorescence (LIF) and laserinduced incandescence (LII). Synergistic effect was observed in $n$-heptane/toluene and isooctane/toluene flames. Kashif et al. [15] studied sooting propensities of binary mixtures in laminar flames. Tang et al. [16] studied the soot particles formation of $n$-heptane/toluene mixtures in laminar premixed burner-stabilized stagnation flames, and found that the doping of toluene resulted in soot inception at lower flame heights and reduced primary particle size of soot aggregates. Park et al. [13] systematically investigated surrogate composition effects on PAHs and soot formation in flames (e.g., n-heptane/iso-octane, $n$-heptane/toluene, iso-octane/toluene, and $n$-heptane/iso-octane/toluene), and developed a detailed PAH formation mechanism for TPRF mixtures (denoted "KAUST-Aramco Mech 1-GS" or simply KAM-GS). However, quantitative analysis of PAHs was not performed because of limitations of their LIF technique [17].

Several kinetic models for TPRFs exist in the literature. Blanquart et al. [10] developed a mechanism for engine relevant fuels, highlighted the importance of acetylene, propyne, propene, and 1,3-butadiene in the formation of PAHs. Marchal et al. [18] developed a model of aromatics and soot formation for large fuel molecules including reactions for benzene and PAHs up to four rings. Raj et al. [19] and Park et al. [13] developed PAHs mechanisms for gasoline surrogate fuels to predict the synergistic effect of PAHs formation. An et al. [20] and Wang et al. [21] presented reduced mechanism for TPRFs, and coupled them with numerical simulations to predict PAHs and soot formation in engines. However, due to the lack of fundamental data for PAHs in TPRF combustion, these kinetic models have been typically validated using pure $n$-heptane, iso-octane, and toluene experimental results or un-quantified data with a focus of predicting trends in PAHs formation [13, 19]. 
Motivated by these gaps in experiments and kinetic models, this work provides speciation data of PAHs during the pyrolysis of two representative TPRF mixtures, i.e., TPRF97.5 and TPRF70 [12], which were formulated to match the octane number and octane sensitivity of high octane and low octane (i.e., naphthas) gasolines, respectively. In studying these TPRF mixtures, the effect of surrogate composition on PAHs formation is eludicated. The aforementioned TPRF kinetic models were validated by comparing mole fraction profiles of benzene and PAHs up to four rings. As an ongiong work to develop the KAUST PAHs kinetic model, the latest version by Park et al. [13] was improved to better match the experimental data in this work and explain the PAHs formation behavior for the two TPRF mixtures.

\section{Experimental and simulation methods}

Pyrolysis of TPRF 97.5 and TPRF 70 at 1 atm was performed in a jet stirred reactor (JSR) at KAUST and in a flow reactor at NSRL in USTC, China. Intermediates from fuel decomposition and aromatics from benzene to PAHs with four rings were measured by GC and SVUV-PI-MBMS. The formulation of the two TPRF mixtures followed the methodology described in Ref. [12] to match the research octane number (RON) and octane sensitivity $(\mathrm{S})$ of a typical high-octane gasoline with $\mathrm{RON}=97.5$ and $\mathrm{S}=10.9$ and a low-octane gasoline (naphtha) $\mathrm{RON}=70, \mathrm{~S}=4$. The molar composition of toluene/iso-octane/ $n$-heptane is $0.285 / 0.365 / 0.35$ for TPRF70 and $0.775 / 0.08 / 0.145$ for TPRF97.5.

The JSR with volume of $76 \mathrm{~cm}^{3}$ and the sampling systems are similar to those of Dagaut et al. [22]. Details of the KAUST JSR is described in [23]. The experiments were conducted at a fuel concentration of $0.25 \%$ and residence time $1 \mathrm{~s}$. The JSR is located in an oven and the temperature of the reactor is measured by a K-type thermocouple. Good temperature homogeneity was observed by moving the thermocouple along the centerline of the reactor. The products are sampled by a sonicthroat gas sampling probe located at the outlet of the reactor and connected to a mechanical pump. The pressure-drop across the orifice is sufficient to prevent further reactions in the sample transfer line. The sample gas is analyzed online using Agilent Refinery Gas Analysis (RGA) and Agilent 
7890B GC. The Agilent RGA system, following ASTM D1945, D1946, and UOP 539 method, with

by TCD and FID detectors was used to quantify $\mathrm{H}_{2}$ and $\mathrm{C} 1-\mathrm{C} 5$ hydrocarbons during TPRF pyrolysis.

The Agilent 7890B system is equipped with an Agilent DB-1 column $(15 \mathrm{~mm} \times 0.320 \mathrm{~mm})$ and an FID to separate and detect PAHs. The total time of the temperature program is 17.833 mins, oven controlled as follows: $1.45^{\circ} \mathrm{C}$ for 6 mins; 2. Then $30^{\circ} \mathrm{C} / \mathrm{min}$ to $100^{\circ} \mathrm{C}$ for $4 \mathrm{mins} ; 3$. then $30^{\circ} \mathrm{C} / \mathrm{min}$ to $280^{\circ} \mathrm{C}$ for 0 min. Identification of PAHs was performed by injecting standard samples. PAHs mole fractions were calculated by calibrating with toluene and applying corresponding effective carbon numbers. The uncertainty is $\pm 5 \%$ for reactant mole fraction, $\pm 15 \%$ for $\mathrm{C}_{1}-\mathrm{C}_{5}$ pyrolysis products , and $\pm 30 \%$ for PAHs. The errors are a result of uncertainty in the mass flow controllers and syringe pump, measurement reproducibility, and uncertainties in gas chromatograph measurements, etc.

TPRF pyrolysis in a flow reactor with inner diameter of $7 \mathrm{~mm}$ was analyzed by SVUV-PIMBMS at NSRL in USTC $[6,24,25]$. The temperature profile of the flow reactor is measured by an S-type thermocouple and denoted by its maximum temperature $\left(\mathrm{T}_{\max }\right)$, which denotes the experimental temperature. The temperature profiles used in simulations are provided in Supplementary Material-1 (SM-1). The uncertainty of $\mathrm{T}_{\max }$ is $\pm 30 \mathrm{~K}$. The total flow rate of the mixture was kept at 1.0 standard liter per minute (SLM) at $298 \mathrm{~K}$. The calculated residence times in the studied temperature range are $1.2-2.0 \times 10^{-1} \mathrm{~s}$. A high fuel mole fraction of 0.0057 was used to improve measurement of PAHs with three and four rings. Mole fractions of reactants and several aromatics from benzene to PAHs with four rings were quantified. Photoionization cross sections (PICSs) for the aromatics were obtained from literature [26-28] or estimated from species with similar structure. The values at 10.5 and $9.5 \mathrm{eV}$ are shown in Table S1 of SM-2. The measurement uncertainty is $\pm 10 \%$ for reactant species, $\pm 25 \%$ for those with measured PICS (benzene, ethylbenzene, styrene, indene, naphthalene), and a factor of 2 for those with estimated PICS (bibenzyl, phenanthrene, and pyrene). Experiments with TPRF 70 and 97.5 were carried out using 
the same experimental setup over the same period of time, the data evaluation procedure is the same for the two datasets, and the photoionization cross sections for the PAHs are from the same source. Although a factor of two in the uncertainty was estimated, the error for the same PAH obtained from the two TPRF mixtures cancels out. Therefore, the experimental observation for the mole fraction difference of the PAHs in the two TPRF mixtures is not affected by experimental uncertainty.

JSR simulations were performed in CHEMKIN-PRO [29] using the perfectly stirred reactor module (transient solver with an end time of $50 \mathrm{~s}$ ). The flow reactor pyrolysis experiments were simulated as a plug flow reactor with the experimentally measured temperature profile as an input boundary condition (i.e., the gas-energy equation was not solved).

\section{Results and discussion}

It is interesting to note the significant difference in toluene composition of the two TPRF fuels; TPRF 70 (28.5\%) has significantly less toluene than TPR97.5 (77.5\%). Conventional knowledge would suggest that TPRF97.5 produces significantly more PAHs than TPRF70 due to the higher toluene content in the former. Experimental results and numerical analysis presented below shed further light on this conventional wisdom.

Mole fractions of reactants (n-heptane, iso-octane, and toluene), $\mathrm{CH}_{4}, \mathrm{C}_{2} \mathrm{H}_{2}, \mathrm{C}_{2} \mathrm{H}_{4}, \mathrm{C}_{3} \mathrm{H}_{6}$, allene, propyne, benzene (A1), ethylbenzene, styrene, indene, and naphthalene (A2) were measured by GC analysis for both TPRFs. Apart from these intermediates, more PAHs were measured by the SVUVPI-MBMS in the flow reactor pyrolysis experiments, such as bibenzyl $\left(\mathrm{C}_{14} \mathrm{H}_{14}\right)$, phenanthrene (A3) and pyrene (A4). The structure of these cyclic intermediates including 1,3-cyclopentadiene and aromatics with one to four rings are shown in Table 1 . The mole fractions of these $\mathrm{C}_{1}$ to $\mathrm{C}_{18}$ intermediates are valuable to examine fuel decomposition chemistry, as well as PAHs growth reactions. In the following discussion, we first evaluate the literature kinetic models for TPRFs by comparison to experimental data. Specifically, discrepancies between predictions of the KAM-GS model and experiments are analyzed. Several modifications of the model are presented to improve 

predictions of fuel decomposition and formation of benzene and A4. Next, the model is used to discuss the pyrolysis chemistry of the two TPRFs, with focusing on PAH characteristics.

Table 1. Major aromatics detected in TPRF pyrolysis in this work.

Name Structure

\subsection{Evaluation of literature kinetic models}

In this section, four kinetic models for TPRFs, i.e., Blanquart [10], Wang [21], Marchal [18], and Park [13] were used to simulate the pyrolysis of TPRF70 in the JSR and flow reactor. The relative amounts of of $n$-hetpane, iso-octane, and toluene are similar in TPRF70, which facilitates investigating interactions among the three fuels. Fuel decomposition profiles, acetylene, allene, A1 and A2 in the JSR, as well as A3 and A4 in the flow reactor were selected as validation targets. Comparisons between the experimental measurements and kinetic modeling simulations from literature models are shown in Fig. 1. Blanquart [10] predicts iso-octane, toluene, acetylene and benzene well, but not the formation of larger PAHs. Narayanaswamy [30] updated Blanquart's mechanism, but the predictions of PAHs weren't improved. The simulated results from Wang [21] under-predict the consumption of the three fuels and the formation of A2 and A3. The accurate prediction of A1 and A4 is fortuitous given that fuel decomposition profiles are notably underpredicted. Marchal [18] well predicts the consumption of toluene, but the consumption of $n$-heptane and iso-octane is under-predicted. In addition, this model predicts higher mole fraction of benzene 
and lower mole fractions of A2-A4. In contrast, Park [13] (KAM-GS) predicts well the consumption of $n$-heptane and iso-octane, but over-predicts the consumption of toluene, and formation of benzene and A4. The prediction of other species in JSR pyrolysis of TPRF70 by the literature models are presented in Fig. S1 of SM-2.

In KAM-GS, the pyrolysis and oxidation of small hydrocarbons were updated with $\mathrm{C}_{0}-\mathrm{C}_{4}$ base chemsitry from AramcoMech 1.3 [31]. KAM-GS accurately captured the synergistic PAH formation characteristics in $n$-heptane/toluene and iso-octane/toluene flames and the experimental trends in formation of larger PAHs in TPRF mixtures. In this work, the Park et al. [13] model (KAM-GS) was selected as the base model for improvement. To match the present set of experimental data, some modifications to the PAH sub-mechanisms were made (details of model modification can be found in Table $\mathrm{S} 1$ of SM-3). Model analysis shows that the rate of $\mathrm{C}_{6} \mathrm{H}_{5} \mathrm{CH}_{3}+\mathrm{H}=\mathrm{A} 1+\mathrm{CH}_{3}$ is too fast in KAMGS, which leads to over-prediction of toluene consumption and benzene formation, as shown in Fig.

1. The rate constant was updated according to Vasu et al. [32]. Several pyrene (A4) formation pathways are present in KAM-GS, but the reaction of two indenyl radicals addition $\left(2 \mathrm{C}_{9} \mathrm{H}_{7}=\mathrm{A} 4+\mathrm{C}_{2} \mathrm{H}_{2}+\mathrm{H}_{2}\right)$ over-predicted $\mathrm{A} 4$ formation. In the toluene pyrolysis mechanism by Yuan et al. [33], the self-combination of two indenyl radicals leads to chrysene, instead of pyrene. To improve pyrene predictions, the original indenyl radicals addition reaction was replaced by reaction $2 \mathrm{C}_{9} \mathrm{H}_{7}=\mathrm{CHRYSEN}+2 \mathrm{H}$ and the reaction rate of $\mathrm{C}_{6} \mathrm{H}_{5} \mathrm{CH}_{2}+\mathrm{C}_{9} \mathrm{H}_{7}=\mathrm{A} 4+2 \mathrm{H}_{2}$ was updated according to prediction of PAHs formation from pyrolysis of both TPRFs. The following comparisons with mixtures are based on the modified KAM-GS mechanism. 

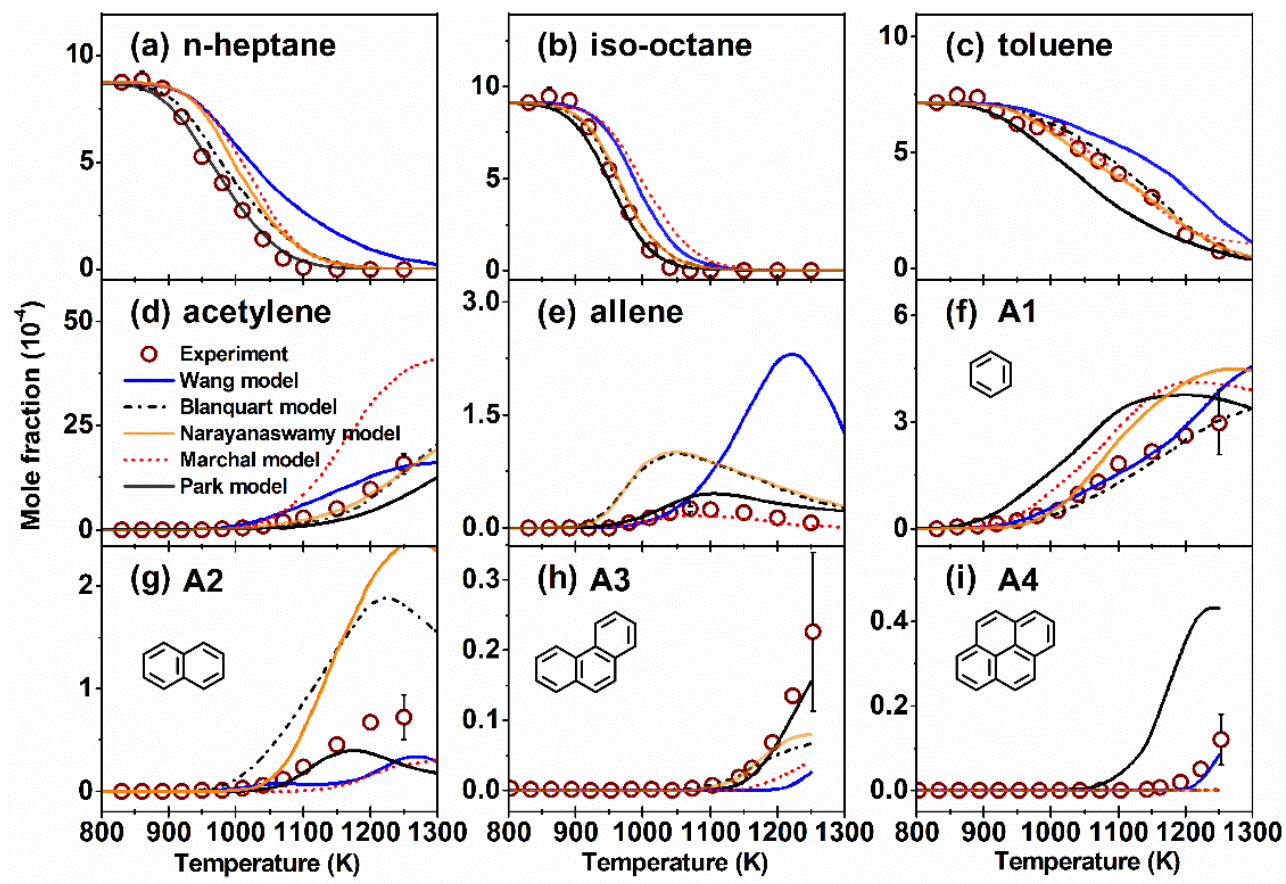

221 Figure 1. Comparison between experimental and simulated [10, 13, 18, 21, 30] mole fractions of 222 TPRF components, acetylene, allene and one to four ring aromatics in TPRF 70 pyrolysis. The 223 experimental data for A3 and A4 were taken from flow reactor pyrolysis while the rest were from 224 JSR pyrolysis.

\subsection{Pyrolysis chemistry of two TPRF mixtures}

\subsubsection{Fuel consumption}

The mole fractions of toluene, $n$-heptane and iso-octane as a function of temperature in the JSR and flow reactor pyrolysis of TPRF70 and TPRF97.5 are shown in Fig. 2. Complete consumption of iso-octane and $n$-heptane in JSR pyrolysis is clearly seen at $1050 \mathrm{~K}$ and $1100 \mathrm{~K}$, respectively. Although $n$-heptane is more reactive than iso-octane under oxidation conditions (i.e., higher rate of consumption), iso-octane has higher rate of consumption during pyrolysis due to the relatively weak tertiary-quaternary carbon bond [35]. This is also supported by the higher total unimolecular decomposition rate constants of $i$ so-octane than those of $n$-heptane (Fig. S2 in SM-2). In TPRF97.5 pyrolysis, the consumption of toluene is much slower and a large amount of toluene is still present at high temperatures (i.e., $1205 \mathrm{~K}$ in JSR pyrolysis). Hypothetical simulations for pyrolysis of pure $n$ heptane, iso-octane, or toluene are shown in Fig. S3 of SM-2 to compare the pyrolysis of these fuel 
components in TPRF mixtures. Toluene consumption is promoted in TPRF mixtures relative to when it is a pure fuel. The decomposition of toluene was strongly promoted when mixed with iso-octane and $n$-heptane, in contrast to the pure toluene decomposition in JSR pyrolysis at around $1130 \mathrm{~K}$. This 240 is attributed to toluene consumption by free radicals (i.e., $\mathrm{H}, \mathrm{CH}_{3}, \mathrm{C}_{2} \mathrm{H}_{3}, \mathrm{C}_{3} \mathrm{H}_{3}, \mathrm{C}_{3} \mathrm{H}_{2}$ ) produced during the pyrolysis of iso-octane and $n$-heptane. iso-Octane is shown to be the most reactive component (i.e., it is consumed completely at the lower temperatures) as a pure component as well as in the TPRF mixtures; its consumption is not greatly affected by blending with $n$-heptane and toluene. $n$-Heptane is consumed at slightly lower temperatures in TPRF97.5 pyrolysis. The rate of production analysis of fuel consumption (Fig. S1 in SM-3) in JSR at $1050 \mathrm{~K}$ indicates that the main pathways of fuel decomposition are similar in both TPRF70 and TPRF97.5 pyrolysis. Generally, the updated KAM-GS simulation shows good agreement with the experimental profiles. Nevertheless, the consumption of toluene was under-estimated for TPRF97.5 pyrolysis in both JSR and flow reactor at low temperature (e.g., before $1200 \mathrm{~K}$ ). Also, the consumption of iso-octane in TPRF70 is slightly over-predicted in flow reactor pyrolysis.

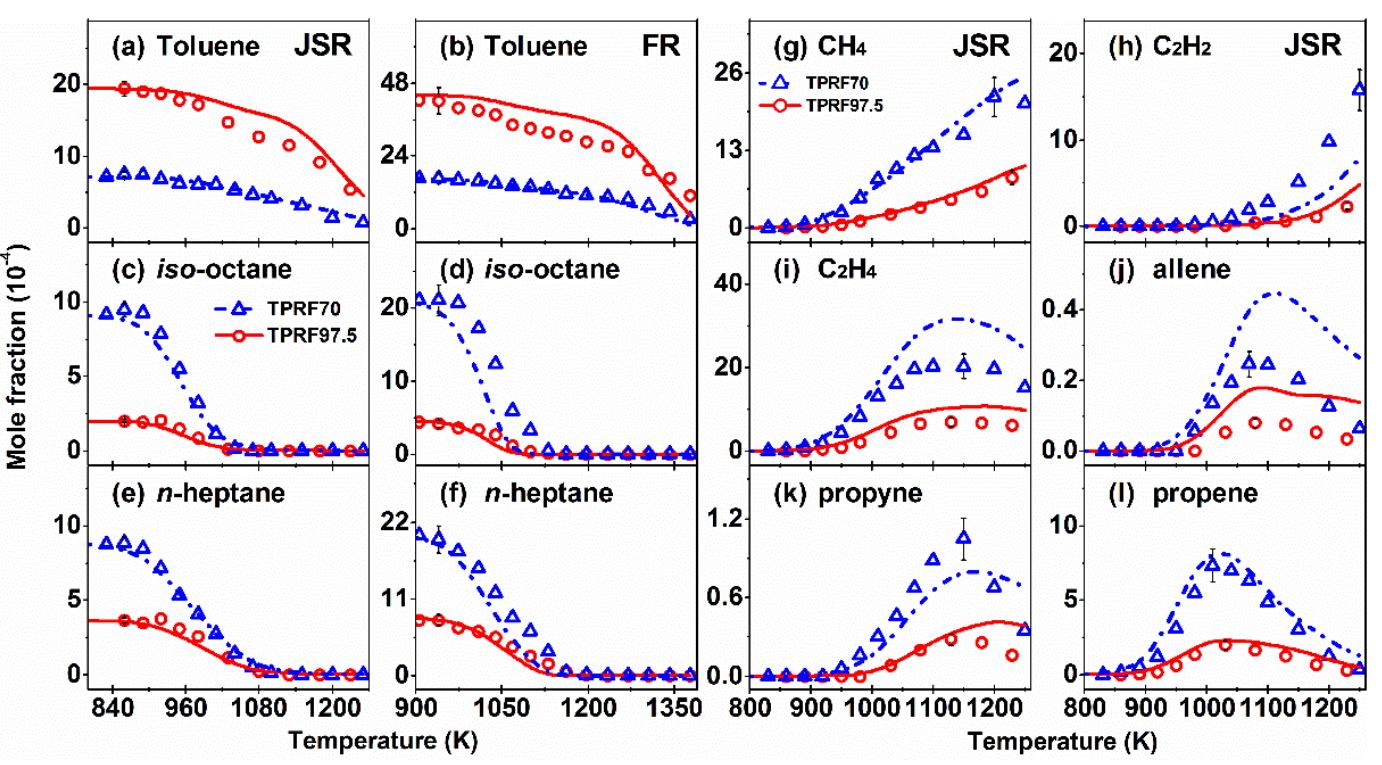

Figure 2. Mole fraction profiles of three components of TPRF (toluene/ iso-octane/ $n$-heptane) in JSR and flow reactor (FR) pyrolysis and mole profiles of small molecules in JSR. Open symbols are experiment results while lines are simulation results. Blue triangles and dash dotted lines are TPRF70 while red circles and solid lines are for TPRF97.5. 
The good prediction of $n$-heptane and iso-octane consumption for the two TPRF mixtures pyrolysis in JSR is also reflected by the mole fractions of small molecule including $\mathrm{CH}_{4}, \mathrm{C}_{2} \mathrm{H}_{2}, \mathrm{C}_{2} \mathrm{H}_{4}$, $\mathrm{C}_{3} \mathrm{H}_{4}$, and $\mathrm{C}_{3} \mathrm{H}_{6}$ in Fig. 2. The overall agreement between the experimental data and the computed data for these small intermediates is satisfactory. These species are produced from iso-octane's and $n$-heptane's unimolecular decompositions and H-atom abstractions, as shown in Fig. S1 of SM-3. The TPRF70 produced more small hydrocarbons than TPRF97.5, as the former contains more isooctane and $n$-heptane. The large production of $\mathrm{C}_{2} \mathrm{H}_{2}$, allene, and propyne in TPRF70 influenes its PAH formation characters, which will be discussed later.

\subsubsection{Formation of first aromatic ring}

The mole fraction profiles of benzene in JSR and flow reactor pyrolysis are shown in Fig. 3a and $3 \mathrm{~b}$. The observed trend for benzene is similar in both JSR and flow reactor pyrolysis. The formation of benzene starts at $900 \mathrm{~K}$ in JSR pyrolysis. In the range of $1050 \mathrm{~K}$ and $1200 \mathrm{~K}$, the concentration of benzene in TPRF70 pyrolysis is slightly higher than that in TPRF97.5 pyrolysis, despite the higher toluene content in TPRF97.5. As mentioned by Park et al. [13], the main source for benzene is the reaction of toluene with $\mathrm{H}$ atoms $\left(\mathrm{C}_{6} \mathrm{H}_{5} \mathrm{CH}_{3}+\mathrm{H}=\mathrm{A} 1+\mathrm{CH}_{3}\right)$ in TPRF mixtures. Nonetheless, the self-combination of propargyl radicals $\left(\mathrm{C}_{3} \mathrm{H}_{3}+\mathrm{C}_{3} \mathrm{H}_{3}=\mathrm{A} 1\right)$ and the reaction of propargyl radical with allyl radical $\left(\mathrm{C}_{3} \mathrm{H}_{3}+\mathrm{C}_{3} \mathrm{H}_{5}-\mathrm{A}=\mathrm{A} 1+2 \mathrm{H}\right)$ also have large contribution to benzene formation in TPRF70 pyrolysis. For example, according to ROP analysis at $1050 \mathrm{~K}$ in JSR (see Figure $\mathrm{S} 1$ in SM-3), $28 \%$ of benzene formation is from $\mathrm{C}_{3} \mathrm{H}_{3}+\mathrm{C}_{3} \mathrm{H}_{5}$-A in TPRF70, but only $3 \%$ in TPRF97.5. The higher concentration of allene and propyne in TPRF70 pyrolysis (Fig. $2 \mathrm{j}$ and $2 \mathrm{k}$ ) leads to higher mole fraction of propargy radical via $\mathrm{H}$-atom abstraction by $\mathrm{H}$ atom and $\mathrm{CH}_{3}$ radical. In addition, more allyl radical $\left(\mathrm{C}_{3} \mathrm{H}_{5}-\mathrm{A}\right)$ is produced in TPRF 70 pyrolysis than TPRF97.5 due to the more formation of propene (Fig. 2l). Thus, the predominance of $\mathrm{C}_{3} \mathrm{H}_{3}+\mathrm{C}_{3} \mathrm{H}_{3}$ pathways in TPRF70 pyrolysis leads to comparable benzene mole fraction, even though TPRF97.5 contains a much higher mole fraction of toluene. In addition, the formation of benzene in JSR pyrolysis of TPRF70 slows 
down after $1200 \mathrm{~K}$, while the benzene mole fraction continues increasing in TPRF97.5. The reaction of toluene with $\mathrm{H}$ atom is the dominant pathway for benzene after $1200 \mathrm{~K}$ in TPRF 97.5, while $\mathrm{C}_{3} \mathrm{H}_{3}+\mathrm{C}_{3} \mathrm{H}_{3}$ reactions become less important. benzyl radical with methyl radical $\left(\mathrm{C}_{6} \mathrm{H}_{5} \mathrm{CH}_{2}+\mathrm{CH}_{3}=\mathrm{C}_{6} \mathrm{H}_{5} \mathrm{C}_{2} \mathrm{H}_{5}\right)$, while benzyl radical is formed from the H-atom abstraction of toluene. The higher concentration of benzyl radical in TPRF97.5 pyrolysis leads to higher mole fraction of ethylbezene than that in TPRF70 pyrolysis. After $1050 \mathrm{~K}$, ethylbezene is mostly consumed by $\mathrm{H}$-atom abstraction and two consecutive steps of dehydrogenation leading to styrene in Fig. 3e and 3f. The model predicts well the mole fraction profiles of ethylbenzene and styrene in both JSR and flow reactor pyrolysis.

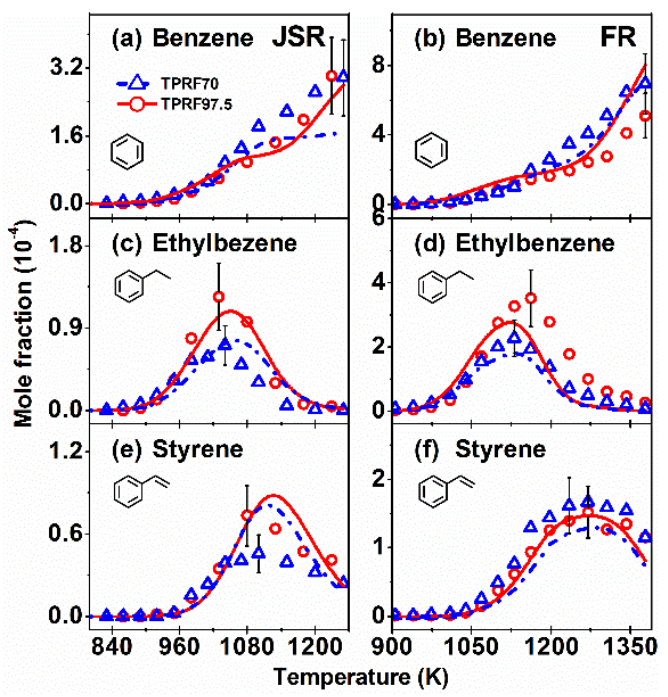

293 Figure 3. The mole fraction profiles of aromatics with one ring (benzene, ethylbenzene, and styrene) in JSR and flow reactor (FR) pyrolysis of two TPRF mixtures. Blue triangles and dash dotted lines are TPRF70 while red circles and solid lines are TPRF 97.5.

\subsubsection{Formation of large PAHs}

Indene $\left(\mathrm{C}_{9} \mathrm{H}_{8}\right)$ plays an important role in PAHs growth because indenyl radical $\left(\mathrm{C}_{9} \mathrm{H}_{7}\right)$, produced by the dehydrogenation of indene, directly reacts with other radicals to produce A2, A3, 
and A4 [7]. Experimental indene mole fractions of the two TPRFs shows opposite trends in the JSR and flow reactor pyrolysis (Fig. 4a and 4b). However, the simulation shows that TPRF97.5 produces more indene than TPRF70 in both reactors. The flux analysis in $1050 \mathrm{~K}$ indicates that the addition of acetylene $\left(\mathrm{C}_{2} \mathrm{H}_{2}\right)$ to benzyl radical $\left(\mathrm{C}_{6} \mathrm{H}_{5} \mathrm{CH}_{2}+\mathrm{C}_{2} \mathrm{H}_{2}=\mathrm{C}_{9} \mathrm{H}_{8}+\mathrm{H}\right)$ contributes to $75 \%$ of indene formation in TPRF97.5 and 66\% in TPRF70 in JSR. The low prediction of indene in TPRF70 may be due to the under-prediction of acetylene in Fig.2h. In addition, the reaction between phenyl (A1-) and allene, $\mathrm{A} 1-+\mathrm{C}_{3} \mathrm{H}_{4}-\mathrm{A}=\mathrm{C}_{9} \mathrm{H}_{8}+\mathrm{H}$, contributes $19 \%$ and $27 \%$ to indene formation in TPRF97.5 and TPRF70, respectively. Although additional reactions of methylindene were added to the model, the model still under-predicts indene profiles, which indicates that additional reactions may be missing.

The mole fractions of naphthalene are shown in Fig. 4c and 4d. Slightly higher mole fraction of naphthalene is produced in TPRF70 than TPRF97.5, in spite of the higher benzyl radical concentration in TPRF97.5. Further flux analysis shows that over $65 \%$ of naphthalene is produced by the dehydrogenation of 1,2-dihydronaphthalenyl radical $\left(\mathrm{C}_{10} \mathrm{H}_{9}\right)$ at $1050 \mathrm{~K}$, meanwhile over $90 \%$ at $1234 \mathrm{~K}$ (Fig. $\mathrm{S} 2$ in $\mathrm{SM}-3) . \mathrm{C}_{10} \mathrm{H}_{9}$ is mainly produced from 1,2-dihydronaphthalene $\left(\mathrm{C}_{10} \mathrm{H}_{10}\right)$. The main pathway for $\mathrm{C}_{10} \mathrm{H}_{10}$ formation is the addition of propargyl radical to benzyl $\left(\mathrm{C}_{6} \mathrm{H}_{5} \mathrm{CH}_{2}+\mathrm{C}_{3} \mathrm{H}_{3}=\mathrm{C}_{10} \mathrm{H}_{10}\right)$. Hence, the higher mole fraction of $\mathrm{C}_{3} \mathrm{H}_{3}$ radical in TPRF70 pyrolysis may be the reason for the slightly higher naphthalene formation than that in TPRF97.5 pyrolysis. The trend of A2 formation in the two TPRF pyrolysis in predicted by the model simulation in JSR pyrolysis. However, the simulation of flow reactor shows that the formation of A2 is close in two TPRF pyrolysis bofore $1350 \mathrm{~K}$, while more A2 is produced during TPRF97.5 pyrolysis after $1350 \mathrm{~K}$.

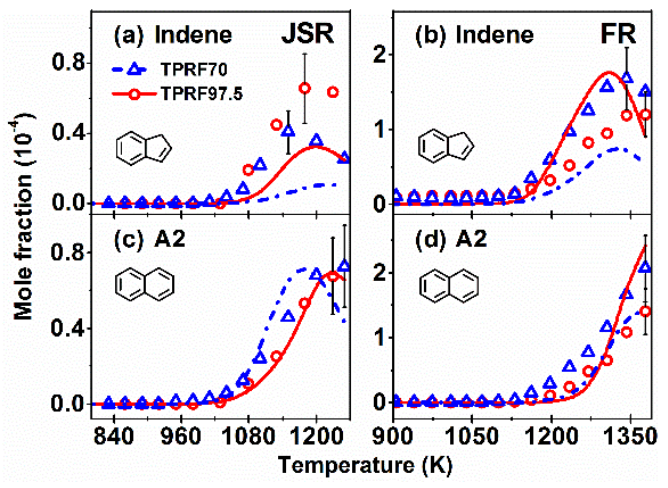


Figure 4. The mole fraction profiles of indene $\left(\mathrm{C}_{9} \mathrm{H}_{8}\right)$ and naphthalene (A2) in JSR and flow reactor (FR) pyrolysis. Blue triangles and dash dotted lines are for TPRF70 while red circles and solid lines are for TPRF97.5.

PAHs with three and four rings were not observed in the JSR pyrolysis of both TPRF mixtures. The SVUV-PI-MBMS measured these intermediates in the flow reactor pyrolysis of both TPRF mixtures. In addition, bibenzyl was also measured in flow reactor pyrolysis. The mole fractions of bibenzyl, phenanthrene and pyrene obtained in flow reactor pyrolysis and model simulations are in good agreement, as shown in Fig. 5. The signal of bibenzyl in TPRF70 pyrolysis was weak, and its prediction by the model was also low (not shown in Fig. 5). In TPRF97.5 pyrolysis, slightly higher phenanthrene and pyrene concentrations are generated because benzyl radical produced from toluene dehydrogenation plays a significant role in PAHs growth. For example, self-combination of benzyl radicals leads to bibenzyl, which undergoes consecutive dehydrogenation reactions to form phenanthrene $\left(\mathrm{C}_{14} \mathrm{H}_{14}=\mathrm{C}_{14} \mathrm{H}_{12}+\mathrm{H}_{2}\right.$ and $\left.\mathrm{C}_{14} \mathrm{H}_{12}=\mathrm{A}_{3}+\mathrm{H}_{2}\right)$. Experimentally, bibenzyl consumption begins around $1200 \mathrm{~K}$ and initiates the production of phenanthrene. The traditional HACA (hydrogen abstraction $-\mathrm{C}_{2} \mathrm{H}_{2}$ addition) mechanism [36] also leads to phenanthrene, and eventually forming pyrene in TPRF70. However, the HACA pathway is much slower compared to the bibenzyl pathway. Instead, the reaction of benzyl radical with indenyl radical $\left(\mathrm{C}_{6} \mathrm{H}_{5} \mathrm{CH}_{2}+\mathrm{C}_{9} \mathrm{H}_{7}=\mathrm{A} 4+2 \mathrm{H}_{2}\right)$ is the main suource for pyrene in pyrolysis of both TPRF70 and TPRF97.5. The reaction rate of $\mathrm{C}_{6} \mathrm{H}_{5} \mathrm{CH}_{2}+\mathrm{C}_{9} \mathrm{H}_{7}=\mathrm{A} 4+2 \mathrm{H}_{2}$ in present model is calculated by Sinha et al.[34], which has a lower reaction rate comparing to Slavinskaya's [37] work. However, it still over-predicts A4 in TPRF97.5 pyrolysis.

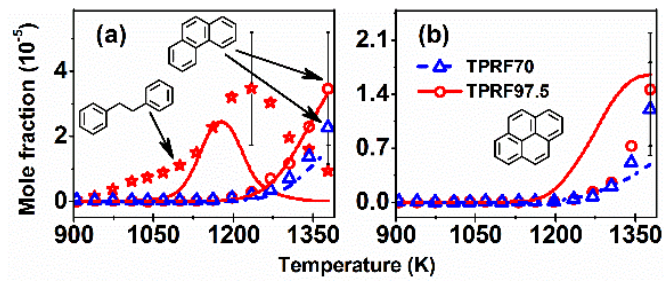


342 Figure 5. The mole fraction profiles of bibenzyl $\left(\mathrm{C}_{14} \mathrm{H}_{14}\right)$, phenanthrene (A3) and pyrene (A4) in 343 flow reactor pyrolysis. Blue triangles and dash dotted lines are for TPRF70 while red circles and 344 solid lines are for TPRF97.5.

\section{4. Conclusions}

PAHs formation characteristics in pyrolysis of two gasoline surrogates, TPRF97.5 representing

347 a high octane number and high octane sensitivity gasoline and TPRF70 representing a low octane 348 number gasoline (naphtha), were studied in a jet-stirred reactor and flow reactor. The mole fraction 349 profiles of the reactants, $\mathrm{C}_{2} \mathrm{H}_{2}, \mathrm{C}_{3} \mathrm{H}_{4}, \mathrm{C}_{3} \mathrm{H}_{6}$, and aromatics including benzene and PAHs up to four 350 rings were measured. Evaluation of literature kinetic models for TPRFs and PAHs formation 351 revealed discrepancies in predicting the formation of PAHs. The KAUST PAH kinetic model was 352 updated to better predict the experimental observations and to analyze fuel decomposition and PAHs 353 profiles. Despite having significantly less toluene, the low octane gasoline surrogate TPRF70 354 produces slightly higher benzene and naphthalene compared to the high octane gasoline surrogate 355 TPRF97.5. On the other hand, the pyrolysis of TPRF97.5 leads to slightly higher production of 356 phenanthrene and pyrene. Both propargyl radical and benzyl radical play critical role in the 357 formation of benzene and naphthalene in TPRF mixtures. In PAHs growth, benzyl radical is a key 358 intermediate in the production of larger PAHs like phenanthrene and pyrene. The latter reaction 359 sequence leads to more large PAHs in the pyrolysis of TPRF surrogates having a high toluene 360 concentration. Further development of the PAHs kinetic model for gasoline surrogates is needed. 361 The experimental data presented in this work are suitable targets for validation of PAH reaction 362 mechanisms.

\section{Acknowledgements}


This work was supported by: King Abdullah University of Science and Technology (KAUST),

Office of Sponsored Research (OSR) under Award No. OSR-2016-CRG5-3022, and Saudi Aramco under the FUELCOM program; National Natural Science Foundation of China (51706217).

\section{Reference}

[1] F. Karagulian, C.A. Belis, C.F.C. Dora, A.M. Prüss-Ustün, S. Bonjour, H. Adair-Rohani, M. Amann, Atmos. Environ. 120 (2015) 475-483.

[2] P. Pant, R.M. Harrison, Atmos. Environ. 77 (2013) 78-97.

[3] G. Karavalakis, D. Short, D. Vu, R.L. Russell, A. Asa-Awuku, H. Jung, K.C. Johnson, T.D. Durbin, Energy 82 (2015) 168-179.

[4] H. Wang, Proc. Combust. Inst. 33 (2011) 41-67.

[5] M. Sarathy, A. Farooq, G.T. Kalghatgi, Prog. Energy Combust. Sci. 65 (2018) 67-108.

[6] L. Zhang, J. Cai, T. Zhang, F. Qi, Combust. Flame 157 (2010) 1686-1697.

[7] Y. Li, L. Zhang, Z. Tian, T. Yuan, J. Wang, B. Yang, F. Qi, Energy Fuels 23 (2009) 1473-1485.

[8] B. Yang, Y. Li, L. Wei, C. Huang, J. Wang, Z. Tian, R. Yang, L. Sheng, Y. Zhang, F. Qi, Proc. Combust. Inst. 31 (2007) 555-563.

[9] F. Battin-Leclerc, Prog. Energy Combust. Sci. 34 (2008) 440-498.

[10] G. Blanquart, P. Pepiot-Desjardins, H. Pitsch, Combust. Flame 156 (2009) 588-607.

[11] S.M. Sarathy, G. Kukkadapu, M. Mehl, T. Javed, A. Ahmed, N. Naser, A. Tekawade, G. Kosiba, M. AlAbbad, E. Singh, Combust. Flame 169 (2016) 171-193.

[12] T. Javed, C. Lee, M. AlAbbad, K. Djebbi, M. Beshir, J. Badra, H. Curran, A. Farooq, Combust. Flame 171 (2016) 223-233.

[13] S. Park, Y. Wang, S.H. Chung, S.M. Sarathy, Combust. Flame 178 (2017) 46-60.

[14] B. Choi, S. Choi, S.-H. Chung, Proc. Combust. Inst. 33 (2011) 609-616.

[15] M. Kashif, J. Bonnety, A. Matynia, P. Da Costa, G. Legros, Combust. Flame 162 (2015) 1840-1847.

[16] Q. Tang, B. Ge, Q. Ni, B. Nie, X. You, Combust. Flame 187 (2018) 239-246.

[17] P. Desgroux, X. Mercier, K.A. Thomson, Proc. Combust. Inst. 34 (2013) 1713-1738.

[18] C. Marchal, J.-L. Delfau, C. Vovelle, G. Moréac, C. Mounai"m-Rousselle, F. Mauss, Proc. Combust. Inst. 32 (2009) 753-759.

[19] A. Raj, I.D.C. Prada, A.A. Amer, S.H. Chung, Combust. Flame 159 (2012) 500-515.

[20] Y.-z. An, Y.-q. Pei, J. Qin, H. Zhao, S.-p. Teng, B. Li, X. Li, Energy 94 (2016) 367-379.

[21] H. Wang, M. Yao, Z. Yue, M. Jia, R.D. Reitz, Combust. Flame 162 (2015) 2390-2404.

[22] P. Dagaut, M. Cathonnet, J.P. Rouan, R. Foulatier, A. Quilgars, J.C. Boettner, F. Gaillard, H. James, J. Phys. E: Sci. Instrum. 19 (1986) 207-209.

[23] B. Chen, Z. Wang, J.-Y. Wang, C. Togbé, P.E. Álvarez Alonso, M. Almalki, M. Mehl, W. Pitz, S.

Wagnon, K. Zhang, G. Kukkadapu, P. Dagaut, M. Sarathy, Phys. Chem. Chem. Phys. submitted for a special issue, Bunsentagung 2018: Kinetics in the Real World (2017).

[24] F. Qi, R. Yang, B. Yang, C. Huang, L. Wei, J. Wang, L. Sheng, Y. Zhang, Rev. Sci. Instrum. 77 (2006) 084101.

[25] F. Qi, Proc. Combust. Inst. 34 (2013) 33-63.

[26] E. Rennie, C. Johnson, J. Parker, D. Holland, D. Shaw, M. Hayes, Chem. Phys. 229 (1998) 107-123.

[27] Z.Y. Zhou, M.F. Xie, Z.D. Wang, F. Qi, Rapid Commun. Mass Spectrom. 23 (2009) 3994-4002.

[28] Z.Y. Zhou, L.D. Zhang, M.F. Xie, Z.D. Wang, D.N. Chen, F. Qi, Rapid Commun. Mass Spectrom. 24 (2010) 1335-1342.

[29] CHEMKIN-PRO 15112, Reaction Design: San Diego, (2012).

[30] K. Narayanaswamy, G. Blanquart, H. Pitsch, Combust. Flame 157 (2010) 1879-1898.

[31] W.K. Metcalfe, S.M. Burke, S.S. Ahmed, H.J. Curran, Int. J. Chem. Kinet. 45 (2013) 638-675.

[32] S.S. Vasu, D.F. Davidson, R.K. Hanson, J. Propul. Power 26 (2010) 776-783.

[33] W. Yuan, Y. Li, P. Dagaut, J. Yang, F. Qi, Combust. Flame 162 (2015) 22-40.

[34] S. Sinha, R.K. Rahman, A. Raj, Phys. Chem. Chem. Phys. 19 (2017) 19262-19278. 
413 [35] N. Atef, G. Kukkadapu, S.Y. Mohamed, M. Al Rashidi, C. Banyon, M. Mehl, K.A. Heufer, E.F. Nasir, A. 414 Alfazazi, A.K. Das, C. K. Westbrook, W. J. Pitz, T. Lu, A. Farooq, C-J. Sung, H. J. Curran, S. M. Sarathy, 415 Combust. Flame 178 (2017) 111-134.

416 [36] M. Frenklach, H. Wang, Proc. Combust. Inst. 23 (1991) 1559-1566.

417 [37] H. Richter, M. Braun-Unkhoff, S. Granata, J. Yu, E. Goos, N. Slavinskaya, P. Frank, W. Green, J. 418 Howard, European Combuation Meeting "ECM2005", Louvain-la-Neuve, Belgium, 2005.

419

420

421

422

423

424

425

426

427

428

429

430

431

432

433

434

435 
(Color figures in electronic version only)

439 Figure 1. Comparison between experimental and simulated $[10,13,18,21]$ mole fractions of TPRF 440 components, acetylene, allene and one to four ring aromatics in TPRF 70 pyrolysis. The 441 experimental data for A3 and A4 were taken from flow reactor pyrolysis while the rest were from 442 JSR pyrolysis.

443 Figure 2. Mole fraction profiles of three components of TPRF (toluene/ iso-octane/ $n$-heptane) in 444 JSR and flow reactor (FR) pyrolysis and mole profiles of small molecules in JSR. Open symbols are 445 experiment results while lines are simulation results. Blue triangles and dash dotted lines are 446 TPRF70 while red circles and solid lines are for TPRF97.5.

447 Figure 3. The mole fraction profiles of aromatics with one ring (benzene, ethylbenzene, and styrene) 448 in JSR and flow reactor (FR) pyrolysis of two TPRF mixtures. Blue triangles and dash dotted lines 449 are TPRF70 while red circles and solid lines are TPRF 97.5.

450 Figure 4. The mole fraction profiles of indene $\left(\mathrm{C}_{9} \mathrm{H}_{8}\right)$ and naphthalene (A2) in JSR and flow reactor 451 (FR) pyrolysis. Blue triangles and dash dotted lines are for TPRF70 while red circles and solid lines 452 are for TPRF97.5

453 Figure 5. The mole fraction profiles of bibenzyl $\left(\mathrm{C}_{14} \mathrm{H}_{14}\right)$, phenanthrene (A3) and pyrene (A4) in 454 flow reactor pyrolysis. Blue triangles and dash dotted lines are for TPRF70 while red circles and 455 solid lines are for TPRF97.5.

\section{Table Caption}

457 Table 1. Major aromatics detected in TPRF pyrolysis in this work.

\section{Supplement Material}

459 SM-1: The temperature profiles of flow reactor; SM-2: The PICSs of species in Table S1, the 460 evaluation of literature models by other species in JSR pyrolysis of TPRF70 in Fig. S1, the reaction 461 rates of unimolecular decomposition of iso-octane and $n$-heptane in Figure S2, and the comparision 462 of fule consumption in pure fuel and TPRF in Figure S3; SM-3: The description of knetic model 463 modification and ROP analysis; SM-4: The detailed knetic model; SM-5: The experimental data. 